\title{
A importância da aplicação de um check-list para elaboração e controle do PCMAT sob a óptica da NR 18
}

\author{
The Importance of Applying a PCMAT Design and Control Checklist from the NR 18 Perspective
}

\author{
Lien Viana Jacudi*, Alex Franco Ferreira
}

Como citar esse artigo. Jacudi, LV; Ferreira, AF. A importância da aplicação de um check-list para elaboração e controle do PCMAT sob a óptica da NR 18. Revist Teccen. 2019 Jul/Dez; 12 (2): 68-74.

\begin{abstract}
Resumo
O setor da Construção Civil é responsável por muitos acidentes de trabalho, devido à exposição de vários fatores de risco. Dessa forma, percebe-se a importância da implementação de medidas preventivas nas construções. O objetivo deste trabalho écriar uma ferramenta eficaz e ágil para avaliação e controle das condições do trabalho nos canteiros de obras da área da construção civil, apresentando a importância da aplicação de um check-listpara elaboração e controle do PCMAT sob a óptica da NR 18. O PCMAT tem como objetivo, além da implantação de uma ferramenta que busca a preservação da saúde e da integridade física do trabalhador, manter sob controle todos os agentes ambientais, com monitoramentos periódicos e por ser um Programa extenso e com um número grande de exigências é importante a aplicação de um checklist para a elaboração e acompanhamento do mesmo. O objetivo é alcançado por meio da revisão bibliográfica sobre o tema abordado, concluindo-se que a aplicação de um check-list para elaboração correta do PCMAT, com o devido cumprimento das medidas preventivas, traz maior segurança e saúde aos colaboradores da Construção Civil.

Palavras-Chave: NR 18, Acidentes do Trabalho, PCMAT, Segurança do Trabalho, Check-List.
\end{abstract}

\begin{abstract}
The construction industry is responsible for many work accidents due to exposure of various risk factors. Thus, we realize the importance of implementing preventive measures in buildings. The objective of this work is to create an efficient and agile tool for assessment and control of working conditions in construction sites, presenting the importance of applying a checklist for the elaboration and control of PCMAT from the perspective of NR. 18. The PCMAT aims, in addition to the implementation of a tool that seeks to preserve the health and physical integrity of the worker, to keep under control all environmental agents, with periodic monitoring and because it is an extensive program with a large number of workers. Requirements It is important to apply a checklist for the preparation and monitoring of it. The objective is achieved through the literature review on the topic, concluding that the application of a checklist for the correct elaboration of the PCMAT, with due compliance with preventive measures, brings greater safety and health to Civil Construction employees.

Keywords: Quadro 2: Check-list - Programa de Condições e Meio Ambiente de Trabalho na Indústria da Construção (Continuação) NR 18, Work Accidents, PCMAT, Work Safety, Check List.
\end{abstract}

\section{Introdução}

O setor da Construção Civil é responsável por muitos acidentes de trabalho, devido à exposição de vários fatores de risco. Entende-se assim, que esse setor tem um alto potencial de risco à saúde do trabalhador. Dessa forma, percebe-se aimportância daimplementação de medidas preventivas nas construções.

Neste trabalho apresentou-se a importância da aplicação de um check-listpara elaboração de um
PCMAT (Programa de Condições e Meio Ambiente de Trabalho na Indústria da Construção), com as exigências dispostas na NR 18. Muitos padrões determinados em norma não são cumpridos, alguns itens de segurança estabelecidos no respectivo PCMAT das obras, muitas vezes, são simplesmente ignorados. Sendo assim, é preciso que os padrões sejam realmente executados, seguindo fielmente ao que está padronizado e registrado em norma, dessa forma um check-list torna-se uma importante ferramenta de controle, fazendo-se possível um melhoramento contínuo com sua aplicação. 
Este trabalho teve por objetivo criar um check-list, uma ferramenta eficaz e ágil para avaliação e controle das condições do trabalho nos canteiros de obras da área da construção civil.

No setor de segurança e saúde do trabalho há uma grande aceitação do uso da metodologia de aplicação de check-list, por ser uma ferramenta de fácil aplicação para quantificar e qualificar o local e as condições de trabalho, além de servir como parâmetro comparativo para as melhorias e avaliações futuras.

Este Trabalho foi realizado de acordo com estudos feitos da NR-18 (2018), observando-se a documentação necessária à construção, a aplicabilidade do mesmo e a criação de um ckeck-list para verificação da implementação, atendendo todas as exigências legais da NR-18.

\section{Acidentes de Trabalho na Construção Civil}

Conforme dispõe o art. 19 da Lei $\mathrm{n}^{\circ}$ 8.213/91, "acidente de trabalho é o que ocorre pelo exercício do trabalho a serviço da empresa, provocando lesão corporal ou perturbação funcional que cause a morte ou a perda ou redução, permanente ou temporária, da capacidade para o trabalho".

As doenças profissionais e/ou ocupacionais equiparam-se a acidentes de trabalho. Os incisos do art. 20 da Lei $n^{\circ} 8.213 / 91$ as conceitua:

Doença profissional, assim entendida a produzida ou desencadeada pelo exercício do trabalho peculiar a determinada atividade e constante da respectiva relação elaborada pelo Ministério do Trabalho e da Previdência Social; Doença do trabalho, assim entendida a adquirida ou desencadeada em função de condições especiais em que o trabalho é realizado e com ele se relacione diretamente, constantedarelaçãomencionadanoincisoI.(Lein.8213,1991)

No ramo da Construção Civil devido à exposição de diversos fatores de riscos e ao alto índice de irregularidade sob a óptica da segurança do trabalho e do meio ambiente de trabalho, há um grande potencial de ocorrência de acidentes.

No Brasil, um acidente de trabalho é estimado a cada 48 segundos. Entre 2012 e 2018, 4,4 milhões de acidentes de trabalho foram registrados. Grande parte dos casos ocorreu na construção civil, o $4^{\circ}$ setor econômico no País com mais ocorrências: 97 mil. Os dados são do Observatório Digital de Saúde e Segurança do Trabalho (OSST), ferramenta do MPT e da OIT, que faz o acompanhamento dos acidentes em tempo real, por meio do chamado "acidentômetro", além de fazer um mapeamento das áreas com maior incidência de casos.

Conforme o Quadro 1, observa-se a quantidade de acidentes do trabalho, por situação do registro e motivo, segundo a Classificação Nacional de Atividades Econômicas (CNAE) de número 4120, que refere-seà Construção de Edifícios, entre os anos de 2015 e 2017. Esses dados foram tirados do Anuário Estatístico de Acidentes do Trabalho da Previdência Social (2017).

Dessa forma, percebe-se a importância da implementação de medidas preventivas nas construções, tendo-se em vista que a NR-18 é de grande importância para a saúde e segurança dos trabalhadores, tornando-se essencial a sua aplicação nos canteiros de obra.

Uma visão geral da NR-18 - Condições e meio Ambiente de Trabalho na Indústria da Construção

A Norma Regulamentadora de $\mathrm{n}^{\circ} 18, \mathrm{NR}-18$, trata de Condições e Meio Ambiente de Trabalho na Indústria da Construção, publicada pela Portaria $\mathrm{MTb}^{\circ} 3.214$, de 08 de junho de 1978, tendo a sua última atualização em 18 de abril de 2018. Esta norma estabelece diretrizes de ordem administrativa, de planejamento e de organização, que objetivam a implementação de medidas de controle e sistemas preventivos de segurança nos processos, nas condições e no meio ambiente de trabalho na Indústria da Construção. Visa a Redução do acentuado número de acidentes de trabalho e doenças ocupacionais envolvidos, melhoria na qualidade dos ambientes de trabalho e melhoria na qualidade dos serviços.

Quadro 1. Quantidade de acidentes do trabalho, por situação do registro e motivo, segundo a Classificação Nacional de Atividades Econômicas (CNAE), no Brasil - 2015/2017

\begin{tabular}{|c|c|c|c|c|c|c|c|c|c|c|c|c|c|c|c|c|c|c|}
\hline \multirow{5}{*}{ CNAE } & \multicolumn{18}{|c|}{ QUANTIDADE DE ACIDENTES DO TRABALHO } \\
\hline & \multirow{3}{*}{\multicolumn{3}{|c|}{ TOTAL }} & \multicolumn{12}{|c|}{ COM CAT REGISTRADA } & \multirow{3}{*}{\multicolumn{3}{|c|}{$\begin{array}{c}\text { SEM CAT } \\
\text { REGISTRADA }\end{array}$}} \\
\hline & & & & \multirow{2}{*}{\multicolumn{3}{|c|}{ TOTAL }} & \multicolumn{9}{|c|}{ MOTIVO } & & & \\
\hline & & & & & & & \multicolumn{3}{|c|}{ Típıco } & \multicolumn{3}{|c|}{ TRANETO } & \multicolumn{3}{|c|}{$\begin{array}{l}\text { DOENÇA DO } \\
\text { TRABALHO }\end{array}$} & & & \\
\hline & 2015 & 2016 & 2017 & 2015 & 2016 & 2017 & 2015 & 2016 & 2017 & 2015 & 2016 & 2017 & 2015 & 2016 & 2017 & 2015 & 2016 & 2017 \\
\hline 4120 & 15.075 & 11.917 & 9.178 & 12.397 & 9.607 & 7.428 & 10.163 & 7.784 & 5.978 & 2.036 & 1.683 & 1.338 & 198 & 140 & 112 & 2.678 & 2.310 & 1.750 \\
\hline
\end{tabular}


Conforme conta no Quadro I da NR-4 (2016), que cita a Relação da Classificação Nacional de Atividades Econômicas - CNAE, com correspondente Grau de Risco - GR para fins de dimensionamento do SESMT, consideram-se atividades da Indústria da Construção, demolição, reparo, pintura, limpeza e manutenção de edifícios em geral, de qualquer número de pavimentos ou tipo de construção, inclusive manutenção de obras de urbanização e paisagismo, entre outros.

Conforme ENIT (2018), na NR-18:

É vedado o ingresso ou a permanência de trabalhadores no canteiro de obras, sem que estejam assegurados pelas medidas previstas nesta NR e compatíveis com a fase da obra. A observância do estabelecido nesta NR não desobriga os empregadores do cumprimento das disposições relativas às condições e meio ambiente de trabalho, determinadas na legislação federal, estadual e/ou municipal, e em outras estabelecidas em negociações coletivas de trabalho.(ENIT, 2018)

De acordo com ENIT (2018), na NR-18, item 18.2, é estabelecido que se deve ter a Comunicação Prévia antes de iniciar uma obra, sendo obrigatória a comunicação à Delegacia Regional do Trabalho. É obrigatório informar o endereço correto da obra; o endereço correto e qualificação (CEI, CGC ou CPF) do contratante, empregador ou condomínio; tipo da obra; datas previstas do início e conclusão da obra; e o número máximo previsto de trabalhadores na obra.

De acordo com a Portaria $\mathrm{n}^{0} 540$, de 25 de maio de 2016, publicado pelo Diário Oficial da União, é determinado que a Comunicação Prévia de Obras, prevista no item 18.2 da NR-18, seja feita por meio do Sistema de Comunicação Prévia de Obras (SCPO), disponível no sítio da internet do Ministério do Trabalho. Esse sistema facilita o cumprimento da obrigação prevista nesta norma.

Conforme ENIT (2018), na NR-18, item 18.3, é apresentado o Programa de Condições e Meio Ambiente de Trabalho na Indústria da Construção (PCMAT), para estabelecimento de metas e prioridades nas ações de Prevenção de Riscos, sendo uma ferramenta que visa a preservação da saúde e da integridade física do trabalhador.

\section{Programa de Condições e Meio Ambiente de Trabalho na Indústria da Construção (PCMAT)}

Segundo ENIT (2018), na NR-18, item 18.3.1, o Programa de Condições e Meio Ambiente de Trabalho (PCMAT), é exigido para as empresas com 20 ou mais funcionários. Esse Programa estabelece metas e prioridades nas ações de Prevenção aos Riscos Ambientais na Indústria da Construção Civil. Observamse dificuldades de implantação na maior parte das empresas da Indústria da Construção que apresentam esse programa, pois muitas vezes, não alcançam os resultados esperados.

O PCMAT tem como objetivo, além da implantação de uma ferramenta que busca a preservação da saúde e da integridade física do trabalhador, manter sob controle todos os agentes ambientais, com monitoramentos periódicos, devendo ser elaborado por profissional legalmente habilitado na área de segurança do trabalho, sendo sua implementação nos estabelecimentos, responsabilidade do empregador (SAMPAIO, 1998).

Sua implementação permite um efetivo gerenciamento do ambiente de trabalho, eficácia no gerenciamento do processo produtivo e orientação aos trabalhadores quanto às atividades e aos riscos envolvidos.

A NR-18 aborda questões como áreas de vivência, medidas de proteção contra quedas de altura, movimentação e transporte de materiais e pessoas, máquinas, equipamentos e ferramentas manuais, ordem e limpeza do canteiro, assim como todas as fases que uma obra pode vir a ter, como demolições, escavações, fundações e desmonte de rochas, armações de aço, estruturas metálicas, entre outros. (ENIT, 2018)

Segundo ENIT (2018), na NR-18, item 18.3.1.1, o PCMAT deve contemplar as exigências contidas na NR-9 - Programa de Prevenção e Riscos Ambientais. Nota-se que devem ser considerados como aspectos importantes para a elaboração do PCMAT a integração de algumas Normas Regulamentadoras.

Sendo assim, torna-se importante citar a relação dessas Normas Regulamentadoras, que complementam a NR-18, como a NR-5 - Comissão Interna de Prevenção de Acidentes (CIPA), a NR-6 -Equipamento de Proteção Individual (EPI), NR-7 - Programa de Controle Médico de Saúde Ocupacional (PCMSO), a NR-9 - Programa de Prevenção e Riscos Ambientais (PPRA), a NR-10 -Segurança em Instalações e Serviços em Eletricidade, a NR-15 - Atividades e Operações Insalubres, a NR 17 - Ergonomia,a NR-23 -Proteção Contra Incêndio, a NR-26 -Sinalização de Segurança e a NR-35 -Trabalho em Altura, entre outras, tendo ciência que uma norma complementa a outra.

A NR-18 define no item 18.33 , as exigências relacionadas à criação da CIPA, a empresa que possuir na mesma cidade um ou mais canteiros de obra com menos de 70 empregados, deve organizar CIPA centralizada, já a empresa que possuir um ou mais canteiros de obra com 70 ou mais empregados em cada estabelecimento, fica obrigada a organizar CIPA por estabelecimento. (Enit, 2018)

Na NR-18, item 18.23.1, cita que a empresa é obrigada a fornecer aos trabalhadores, gratuitamente, EPI adequado ao risco e em perfeito estado de conservação e funcionamento, consoante as disposições contidas na 
NR 6 - Equipamentos de Proteção Individual - EPI. (ENIT, 2018)

Conforme ENIT (2017), na NR-9, item 9.1.3, o PPRA é parte integrante do conjunto mais amplo das iniciativas da empresa no campo da preservação da saúde e da integridade dos trabalhadores, devendo estar articulado com o disposto nas demais NR's, em especial com o Programa de Controle Médico de Saúde Ocupacional (PCMSO) previsto na NR-7.

Segundo ENIT (2018), na NR-18, item 18.21.1, fala sobre a relação que a norma tem com a NR-10, que exige que as execuções das instalações elétricas temporárias e definitivas devem atender ao disposto da Norma Regulamentadora $\mathrm{n}^{\circ} 10$ (NR-10) - Segurança em Instalações e Serviços em Eletricidade - do Ministério do Trabalho.

$\mathrm{Na}$ NR-18, item 18.6.16, descreve que na execução de escavações e fundações sob ar comprimido, deve ser obedecido o disposto no Anexo $\mathrm{n}^{\circ} 6$ da NR 15 - Atividades e Operações Insalubres. (ENIT, 2018)

De acordo com ENIT (2018), na NR-17, item 17.1, a norma visa estabelecer parâmetros que permitam a adaptação das condições de trabalho às características psicofisiológicas dos trabalhadores, de modo a proporcionar um máximo de conforto, segurança e desempenho eficiente. Já o item 17.1.2 desta Norma, afirma que para a avaliação desta adaptação de trabalho, cabe ao empregador realizar a análise ergonômica do trabalho.

O item 18.26 da NR-18 é voltado para a Proteção Contra Incêndio nos canteiros de obras, para atender este item é necessário a adoção de medidas que atendam, de forma eficaz, às necessidades de prevenção e combate a incêndio, descrevendo as orientações. Observando-se a relação da NR-23 com essa norma. (ENIT, 2018)

Conforme ENIT (2018), na NR-18, item 18.27, observa-se a relação da NR-18 com a NR-26, onde se encontram as orientações para a Sinalização de Segurança no canteiro de obras.

De acordo com ENIT (2016), NR-35, item 35.1.2, considera-se trabalho em altura toda atividade executada acima de 2,00 m (dois metros) do nível inferior, onde haja risco de queda. Nota-se então, que a maior parte das obras que são realizadas possui trabalhos em altura, e deve-se aplicar esta norma dentro da construção. Sendo uma das exigências das empresas o Treinamento de Trabalho em Altura para os colaboradores que trabalham acima de dois metros do nível inferior.

Percebe-se então que na elaboração do PCMAT é preciso anexar essas outras exigências contidas nas normas citadas, como o Programa de Prevenção e Riscos Ambientais (PPRA), o Programa de Controle Médico de Saúde Ocupacional (PCMSO) e a Análise Ergonômica do Trabalho (AET), o Certificado de Trabalho em Altura, a Lista de EPI, ente outros, sendo primordial o cumprimento e a avaliação das mesmas.
Segundo ENIT (2018), na NR-18, item 18.3.1.2, o PCMAT deve ser mantido no estabelecimento à disposição do órgão regional do Ministério do Trabalho e Emprego - MTE.

\section{Integram o PCMAT:}

a) memorial sobre condições e meio ambiente de trabalho nas atividades e operações, levando-se em consideração riscos de acidentes e de doenças do trabalho e suas respectivas medidas preventivas; b) projeto de execução das proteções coletivas em conformidade com as etapas de execução da obra; c) especificação técnica das proteções coletivas e individuais a serem utilizadas; d) cronograma de implantação das medidas preventivas definidas no PCMAT em conformidade com as etapas de execução da obra; e) layout inicial e atualizado do canteiro de obras e/ ou frente de trabalho, contemplando, inclusive, previsão de dimensionamento das áreas de vivência; f) programa educativo contemplando a temática de prevenção de acidentes e doenças do trabalho, com sua carga horária. (ENIT, 2018)

O memorial é um documento que aborda o que será feito na obra, como será realizado o trabalho, as condições da execução das tarefas, assim como todas as especificações técnicas para essa execução, considerando-se todos os riscos de acidentes e doenças do trabalho e as medidas preventivas para tais riscos.

No projeto de execução das proteções coletivas e individuais, devem-se ter detalhes que facilitem a compreensão dos envolvidos. O mesmo permite a facilidade na montagem, instalação e desmontagem dos equipamentos com todas as definições e medidas dos elementos, permite-se também a eliminação das possibilidades de acidentes de trabalho e possíveis riscos adicionais.

Quanto às especificações técnicas das proteções coletivas e individuais, é um item importante da norma, pois para cada proteção existe um estudo detalhado contendo os tamanhos, o Certificado de Aprovação (CA), a forma de utilização, os componentes de cada equipamento, entre outros itens, que para a correta utilização precisam ser observadas frequentemente.

O PCMAT é um programa que fica em constantes revisões, pois a cada etapa de execução da obra deve ser atualizado e complementado. Dessa forma, é necessário o acompanhamento do cronograma para que as medidas preventivas estejam em conformidade com a cada fase da obra.

Deve-se ter um layout inicial do canteiro de obra, com a localização de todas as instalações, como escritório, áreas de vivência, banheiros, vestiário, refeitório, e todos os setores previstos. O mesmo deve ser atualizado toda vez que ocorrer alguma mudança. É importante que seja claro para compreensão da equipe.

O Programa educativo deve conter os cursos e treinamentos que foram realizados com os colaboradores 
de uma obra e deve contemplar os temas de prevenção de acidentes e doenças do trabalho, com o conteúdo programático, período e carga horária.

O desenvolvimento do programa PCMAT, faz com que surjam vários projetos que devem sempre estar vinculados a uma proposta de ação, proporcionando a melhoria das condições de trabalho. E são esperados objetivos concretos que possam ser medidos quantitativamente e/ou qualitativamente, sempre limitados no tempo (duração da obra) e que possam sempre representar, expansão, modernização ou aperfeiçoamento da ação desejada.

Para conceber o PCMAT deve-se levar em conta o compromisso da alta direção da empresa com o programa por meio da Política de Segurança e Saúde. Deve-se fazer uma análise criteriosa de antecipação e reconhecimento dos riscos, uma pesquisa bibliográfica sobre o tema nos aspectos técnicos e legais e o perfil da mão de obra, abordando questões sobre o nível de conhecimento do trabalhador na área de segurança e saúde, hábitos e costumes, escolaridade, dentre outras.

ConformeENIT (2018), na NR-18, item 18.28, todos os empregados devem receber treinamentos admissionais e periódicos, visando a garantir a execução de suas atividades com segurança.

Os treinamentos ministrados aos colaboradores devem ter a definição do conteúdo programático, com sua carga horária e material instrucional; é necessário definir o tipo do treinamento, sendo introdutório, gerenciamento ou por categoria profissional e deve-se definir a peridiocidade dos mesmos.

Uma elaboração correta e adequada do PCMAT permite que em casos de fiscalização na obra, não se tenham problemas fiscais, como infrações e multas. É necessário que o PCMAT esteja completo e preciso, possuindo as análises de riscos, cronogramas, avaliações confiáveis, projetos de proteção coletiva, atualização conforme andamento das obras ou de outras alterações, entre outras exigências contidas nesta norma.

Assim, o não cumprimento das exigências contidas nessa norma, pode levar a responsabilidades de ordem Administrativa, como multas, embargo ou interdição da obra; Trabalhista e Previdenciária, como pagamentos de adicionais de insalubridade, ação civil pública; Tributária, como o aumento da alíquota do Seguro de Acidente do Trabalho (SAT) ou Fator Acidentário de Prevenção (FAP); e até mesmo Civil e Criminal.

Dessa forma, a aplicação do PCMAT traz benefícios como menos risco de ações indenizatórias; proteção para a imagem da empresa; maior controle dos perigos e riscos de acidentes; prevenção de acidentes de trabalho; melhoria na produtividade; redução com gastos de Seguro Acidente do Trabalho; previne despesas patrimoniais; entre diversos outros benefícios.

ANR-18 trazem sua publicação todas as exigências em cada fase de uma obra, desde áreas de vivência até a ordem e limpeza do local, sabendo-se que em cada obra será aplicado o item de norma correspondente. Devido o PCMAT ser um Programa extenso e com um número grande de exigências é importante a aplicação de um check-list para a elaboração e acompanhamento do mesmo.

\section{Check-list ou lista de verificação}

Check-list é uma lista de verificação que se baseia em itens e marcações do que foi realizado e o que ainda precisa se realizar. É uma ferramenta estratégica para o cumprimento de demandas. As suas funções são diversas e os seus benefícios trazem produtividade, eficiência e

Quadro 2. Check-list - Programa de Condições e Meio Ambiente de Trabalho na Indústria da Construção

\begin{tabular}{|c|c|c|c|c|c|c|}
\hline \multicolumn{7}{|c|}{$\begin{array}{c}\text { Check-list NR-18 - PCMAT (Programa de Condições e Meio Ambiente de Trabalho na Indústria da Construção) } \\
\text { Dados da Inspecaão }\end{array}$} \\
\hline \multicolumn{3}{|c|}{ Empresa: } & \multicolumn{4}{|c|}{ Data: } \\
\hline \multicolumn{7}{|c|}{ Setor: } \\
\hline \multicolumn{7}{|c|}{ Local: } \\
\hline \multicolumn{7}{|c|}{ Responsável Técnico: } \\
\hline пЕМ & $\begin{array}{l}\text { ITEM DA } \\
\text { NORMA }\end{array}$ & DESCRIÇÃO & c & NC & NA & OB SERVAÇÃO \\
\hline 1 & 18.21 & $\begin{array}{l}\text { Houve a comunicaçäo prévia à Delegacia Regional do trabalho r eferente a ender eço da } \\
\text { obra, endereço correto equal ificạ̧ao do contratante, emregador ou condomínio, tipo de } \\
\text { obra, datas de início e conclusäo, númer o máximo previs to de trabalhadores? }\end{array}$ & & & & \\
\hline 2 & 18.3.1. & $\begin{array}{l}\text { Tendo } 20 \text { Trabalhadores ou mais no estabelecimento, foi elaborado o Programa de } \\
\text { Condiçöes e Meio Ambiente de Trabalho na Indústria da Const ução. PCMAT? }\end{array}$ & & & & \\
\hline 3 & 18.3.1.1. & $\begin{array}{l}\text { O PCMAT contempla as Exigências da NR } 9 \text { - Programa de Prevençäo e Riscos } \\
\text { Ambientais - PPRA? }\end{array}$ & & & & \\
\hline 4 & 18.3 .12 & $\begin{array}{l}\text { O PCMAT está a disposição do Ministério do Trabalho e Emprego - MTE no } \\
\text { estabelecimento? }\end{array}$ & & & & \\
\hline 5 & 18.3.2. & $\begin{array}{l}\text { O PCMAT foi elaborado e executado por profissional legalmente habilitado na área de } \\
\text { Segurança do Trabalho? }\end{array}$ & & & & \\
\hline
\end{tabular}


Quadro 2. Check-list - Programa de Condições e Meio Ambiente de Trabalho na Indústria da Construção (Continuação)

\begin{tabular}{|c|c|c|c|c|c|c|}
\hline \multirow{2}{*}{\multicolumn{7}{|c|}{$\begin{array}{l}\text { Check-list NR-18 - PCMAT (Programa de Condiç̃oes e Meio Ambiente de Trabalho na Indústria da Construção) } \\
\text { Dados da Inspecẫo }\end{array}$}} \\
\hline & & & & & & \\
\hline \multicolumn{3}{|c|}{ Empresa: } & \multicolumn{4}{|c|}{ Data: } \\
\hline \multicolumn{7}{|c|}{ Setor: } \\
\hline \multicolumn{7}{|c|}{ Local: } \\
\hline \multicolumn{7}{|c|}{ Responsável Técnico: } \\
\hline TЕM & $\begin{array}{l}\text { ITEM DA } \\
\text { NORMA }\end{array}$ & DESCRIÇÃO & c & NC & NA & OBSERVAÇÃO \\
\hline 6 & 18.3.4. a) & $\begin{array}{l}\text { O PCMAT possui memorial sobre condiçöes e meio ambiente nas atividades e } \\
\text { operaçöes, levando-se em consider açäo riscos de acidentes e de doenças e suas } \\
\text { respectivas medidas preventivas? }\end{array}$ & & & & \\
\hline 7 & $18.3 .4 \mathrm{~b})$ & $\begin{array}{l}\text { O PCMAT possui projeto de execuçäo das proteçöes coletivas em conformidade com as } \\
\text { etapas da execuçäo da obra? }\end{array}$ & & & & \\
\hline 8 & $18.3 .4 \mathrm{c})$ & $\begin{array}{l}\text { O PCMAT possui especificaçäo técnica das proteçöes coletivas e individuais a serem } \\
\text { utilizadas? }\end{array}$ & & & & \\
\hline 9 & $18.3 .4 \mathrm{~d})$ & $\begin{array}{l}\text { O PCMAT possui cronograme de implantaçäo das medidas preventivas em } \\
\text { conformidade com as etapas de execuçäo da obra? }\end{array}$ & & & & \\
\hline 10 & 18.3.4 e) & $\begin{array}{l}\text { O PCMAT possui layout inicial do canteiro da obra, contemplando, inclusive, previs ão do } \\
\text { dimensionamento das áreas de vivênda? }\end{array}$ & & & & \\
\hline 11 & $18.3 .4 \mathrm{f})$ & $\begin{array}{l}\text { O PCMAT possui programe educativo contemplando a temática de prevenção de } \\
\text { acidentes e doenças do trabalho, com sua carga horária? }\end{array}$ & & & & \\
\hline 12 & 18.4.1 a) & O canteiro de obra possui instalaçöes s anitárias? & & & & \\
\hline 13 & $18.4 .1 \mathrm{~b})$ & O canteiro de obra possui instalacões ves tiário? & & & & \\
\hline 14 & $18.4 .1 \mathrm{c})$ & O canteiro de obra possui alojamento? (exigido em cas o de trabalhadores alojados) & & & & \\
\hline 15 & 18.4.1d) & O canteiro de obra possui local para refei öes? & & & & \\
\hline 16 & $18.4 .1 \mathrm{e}$ & O canteiro de obra possui cozinha? (exigido quando há preparo de refeiç̄es) & & & & \\
\hline 17 & $18.4 .1 \mathrm{f})$ & O canteiro de obra possui Lavanderia? (exigido em cas o de trabalhadores alojados) & & & & \\
\hline 18 & $18.4 .1 \mathrm{~g})$ & O canteiro de obra possui área de lazer? (exigido em cas o de trabslhadores alojados) & & & & \\
\hline 19 & 18.4.1 h) & $\begin{array}{l}\text { O canteiro de obra possui ambulatório? (exigido quando se trata de frentes de trabalho } \\
\text { com } 50 \text { (cinquenta) ou mais trabalhadores) }\end{array}$ & & & & \\
\hline
\end{tabular}

otimização dos processos na empresa e é um documento que seu custo é quase que "zero". (Santos, 2011)

Quando o Check-list é utilizado na área de Segurança do Trabalho, ele é ainda mais eficaz, pois permite observar quais os itens da norma estão conformes e quais não estão promovendo uma melhor verificação do local e permitindo que a empresa se adéque para que não ocorram acidentes de trabalho e até mesmo multas que possam ser aplicadas em uma auditoria.

\section{Elaboração do Check-list aplicado a NR- 18}

Para padronização e cumprimento da NR-18 em um canteiro de obra foi elaborado um check-list, para visualização e conferência dos documentos e itens a serem cumpridos. Esse check-list pode ser observado no Quadro 2: Check-list - Programa de Condições e Meio Ambiente de Trabalho na Indústria da Construção. O mesmo contémquatro colunas do lado direito, a serem preenchidas pelo responsável técnico de forma a verificar a real situação das condições de trabalho no canteiro de obras, bem como as correções a serem realizadas no local. legenda:

As referidas colunas apresentam a seguinte

C - Conforme. Indicando que a condição está dentro do padrão desejável, não possuindo pendências.

$\mathrm{NC}$ - Não Conforme. Indica que a situação está fora do padrão estabelecido em norma e que necessita de atenção e aplicação de recursos para que torne ao padrão desejado.

NA - Não se Aplica. Indicando que o item do check-list não se aplica à situação.

Observação - Observações a serem feitas, caso o item não esteja conforme, assim como indicações de medidas corretivas para tal.

\section{Resultados esperados e discussões}

Para melhor gestão da segurança e saúde do 
trabalhadorno canteiro de obra, assim comocumprimento das exigências contidas na NR-18, a proposta da elaboração de um check-list precisa ser apresentada e aplicada em partes, para evitar a resistência às mudanças. Com a implantação do check-list apresentado nesse trabalho, seria possível realizar as construções dentro dos padrões exigidos, com maior segurança e não tendo gastos excedentes com imprevistos, pois o mesmo permite controle e monitoramento do que está sendo gerenciado, agregando segurança, qualidade, baixo custo e satisfação das partes interessadas do projeto.

As construtoras que aderirem a essa prática, tendem a obter maior produtividade, maior lucro, cumprimento dos prazos, melhor qualidade e maior segurança e saúde do trabalhador, permitindo a integridade do mesmo. Uma empresa que pretende ter sucesso e ser competitiva deve estar equiparada aos seus concorrentes e buscar sempre novas metodologias para aperfeiçoamento e melhoria continua de seus processos.

\section{Conclusão e considerações finais}

Observa-se que o objetivo deste trabalho é alcançado por meio da revisão bibliográfica sobre o tema abordado, elaborando-se um check-list, ferramenta eficaz e ágil para avaliação, elaboração e controle das condições do trabalho nos canteiros de obras, servindo como uma ferramenta de melhoramento contínuo.

Sabe-se que o setor da Construção Civil é responsável por diversos acidentes de trabalho, e assim, sem dúvidas a gestão e cumprimento das medidas preventivas da segurança e saúde do trabalho é incontestável. Dessa forma, percebe-se a importância da NR-18 para a Indústria da construção, pois com a elaboração e aplicação do PCMAT no canteiro de obra, são evitados acidentes e imprevistos no local, mantendo um ambiente de trabalho mais seguro para o trabalhador e evitando atrasos e prejuízos na execução, que poderiam vir a ocorrer.

Conclui-se que a aplicação de um check-list para elaboração correta do PCMAT sob a óptica da NR18, assim como o devido cumprimento das medidas preventivas, pode trazer maior segurança e saúde aos colaboradores da Construção Civil, prevenindo e/ou reduzindo riscos de acidentes e doenças ocupacionais, bem como promover melhores condições de trabalho, visando sempre o um ambiente seguro e saudável para os funcionários e, consequentemente, cumprindo a legislação vigente.

\section{Referências Bibliográficas}

ENIT. Escola Nacional da Inspeção do Trabalho. Norma Regulamentadora $\mathrm{N}^{\circ} 4$ (2016).Serviços Especializados em Engenharia de Segurança e em Medicina do Trabalho.

Disponível em: <https://enit.trabalho.gov.br/portal/images/Arquivos_SST/ SST_NR/NR-04.pdf> Acesso em 23 de Setembro de 2019.

.Norma Regulamentadora $N^{\circ} 7$ (2018). Programa de Controle Médico de Saúde Ocupacional.

Disponível em: <https://enit.trabalho.gov.br/portal/images/Arquivos_SST/ SST NR/NR-07.pdf> Acesso em 25 de Setembro de 2019.

Norma Regulamentadora No 9 (2017). Programa de Prevenção de

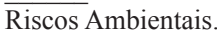

Disponível em: <https:/enit.trabalho.gov.br/portal/images/Arquivos_SST/ SST_NR/NR-09.pdf> Acesso em 25 de Setembro de 2019.

. Norma Regulamentadora $N^{\circ} 18$ (2018). Condições e meio Ambiente de Trabalho na Indústria da Construção.

Disponível em: <https://enit.trabalho.gov.br/portal/images/Arquivos_SST/ SST_NR/NR-18.pdf> Acesso em 23 de Setembro de 2019.

. Norma Regulamentadora $\mathrm{N}^{\circ} 35$ (2016). Trabalho em Altura. Disponível em: <https://enit.trabalho.gov.br/portal/images/Arquivos_SST/ SST_NR/NR-35.pdf> Acesso em 01 de Outubro de 2019.

Lei n. 8213, de 24 de julho de 1991. Dispõe sobre os Planos de Benefícios da Previdência Social e dá outras providências. Diário Oficial da União. Brasília, DF.

OSST. Observatório Digital de Saúde e Segurança do Trabalho (2019). Disponível em: <https://observatoriosst.mpt.mp.br> Acesso em 23 de Setembro de 2019.

Portaria n. 540, de 25 de maio de 2016. Determina a utilização do Sistema de Comunicação de Obras - SCPO e dá outras providências. Diário Oficial da União. Brasília, DF.

Sampaio, José Carlos de Arruda. PCMAT: Programa de Condições e Meio Ambiente do Trabalho na Indústria da Construção. 1. Ed., SindusCon-SP, São Paulo: Pini, 1998.

Santos, José Eduardo Mendonça. (2011). Checklist. Jornal Português de Gastrenterologia , 18(2), 93-94. Recuperado em 02 de outubro de 2019 , de http://www.scielo.mec.pt/scielo.php?script=sci_arttext\&pid=S0872$81782011000200010 \& \operatorname{lng}=$ pt\&tlng $=$ pt. 